\title{
A MULTI-CRITERIA ANALYSIS AS A RATIONAL EVALUATION PROCESS FOR BUILDING A NEW HIGHWAY IN ITALY
}

\author{
ARMANDO CARTENII ${ }^{1}$, ILARIA HENKE ${ }^{2}$, FEDERICA MALLOZZI ${ }^{2}$ \& CLORINDA MOLITIERNO $^{1}$ \\ ${ }^{1}$ Department of Engineering, University of Campania "Luigi Vanvitelli”, Italy \\ ${ }^{2}$ Department of Civil, Construction and Environmental Engineering, University of Naples "Federico II", Italy
}

\begin{abstract}
The low accessibility of transportation to the main Italian touristic places (during the summer period) produces road congestion that is often high and negative environmental impacts (externalities). This is the case of the coastal area between Cesena and Venice, which is particularly affected by this phenomenon because of a unique local road, the Romea: it allows car trips among all these touristic places. Beginning from these considerations, the realization of a new highway was proposed, to improve transport accessibility to this area. A Multi-Criteria Analysis (MCA) was identified as the rational evaluation process to verify the sustainability (economic, social and environmental) of this transportation project. The aim of this paper is to describe the MCA evaluation analyses applied to this case study, underlining the main results obtained. One of the main findings of the research was the applied evaluation methodology. A rational and participated weights definition criterion process was implemented, through a "Delphi method" within a Public Engagement process. The MCA results show that the best design alternative is the construction of a highway plus the realization of a "green-way". Furthermore, we found that the estimated non-user's benefit incidence was about $80 \%$ of the total, underlining the appropriateness in using this evaluation method, useful to better quantify non-monetary externalities (versus the cost-benefit analysis). Finally, to verify the robustness of the results we also performed a sensitivity analysis, confirming the main results.

Keywords: evaluation, cost-benefit analysis, public engagement, sustainable mobility, transportation planning, environmental impact, sustainability, road planning, Italian roadways, tourist areas.
\end{abstract}

\section{INTRODUCTION}

Recently, in Italy, investment in transportation infrastructure was progressively reduced. Therefore, the Italian government started a new "transport planning season". In 2016, the document "Connettere l'Italia: Strategie per le infrastrutture di trasporto e logistica" [Connecting Italy: Strategies for transportation infrastructure and logistics] defined the aim, the strategy and the actions of the new infrastructure policy in Italy. In 2017 a new act, "Connettere l'Italia: fabbisogni e progetti infrastrutturali" [Connecting Italy: needs and infrastructure projects], defined the priority and the main transport-related interventions to be developed. Finally, in 2018, through the act "Connettere l'Italia: lo stato di attuazione di programmi per le infrastrutture di trasporto e logistica" [Connecting Italy: The state of implementation on programs regarding transportation infrastructure and logistics] defined the financial sources needed to develop the transportation priority that was previously defined. Moreover, the Italian government recently approved the "Guidelines for assessment of Investment Projects". The national guidelines, in compliance with the EU guidelines [1], define the methodologies needed to develop both the ex-ante and ex-post evaluation. These methodologies are based on quantitative analysis techniques [2], [3].

In the national guidelines, both Cost-Benefit Analyses (CBA) and Multi-Criteria Analyses (MCA) were suggested as rational evaluation methods. It is known that CBA methods are more standardized (e.g. through the EU guidelines), reducing the risk of planning fallacy; however, CBAs tend to underestimate non-monetary impacts (externalities). For 
example, there are environmental impacts, landscape impacts and the social impact [4]-[7]. On the contrary, the MCA is more suitable for non-users and non-monetary impact estimation, but there are no national and/or EU official guidelines: This does not allow standardization of procedures, increasing the risk of planning fallacy.

Furthermore, one of the main issues in the Italian transport system is the low accessibility to the many summer tourism places, which often suffer from high road congestion and negative environmental impacts (externalities). This is the case in the coastal area between Cesena and Venice which is particularly affected by this phenomenon because of a unique local road, named the "Romea", that allows for car trips among all the touristic places of the area. In accordance with national transport programming, a new highway was proposed, aimed at improving transportation accessibility of the area. The MCA was identified as the rational evaluation process to verify the sustainability (economic, social and environmental) of this project [8]-[10].

Based on these considerations, the aim of the paper was to describe the MCA evaluation analyses made in 2018 and apply it to this case study, underlining the main results obtained. One of the main findings of the research was the applied evaluation methodology. A rational and participated weights definition criterion process was implemented, through a "Delphi method" within a Public Engagement process.

This paper is organized as follows: in Section 2, the case study and MCA methodology are described; in Section 3, the MCA is applied and some results are reported. Finally, conclusions are discussed in Section 4.

\section{THE PROPOSED METHODOLOGY: THE MULTI-CRITERIA ANALYSIS}

The proposed methodology of our MCA is described in Fig. 1. Different activities were proposed: The first one is to define the aims of the evaluation (e.g. environmental, social, transportation), followed by the defining the project alternatives (design scenarios). The third activity is to define the criteria and/or sub-criteria that are useful to compare the different project scenarios. All the scenarios and criteria together define the "evaluation matrix", where the generic element $I_{i j}$ is the value (quantitative or qualitative) of the indicator $I$ relative to the criteria $i$ (e.g. investment cost) for the scenario $j$ (e.g. the new highway scenario).

The next activity is the definition of the weights associated to each criterion defined. This activity, in a rational decision-making process, must be defined through stakeholder engagement (a participated process). The estimation of the Measures Of Effectiveness (MOE) is the activity useful to compare the design scenarios and choose the best solution to implement. This activity is performed through quantitative methods, and use of models able to estimate both costs and the benefits produced by the generic design scenario. Finally, a sensitivity analysis is performed to verify the robustness of the results.

\section{THE APPLICATION CASE STUDY: IDENTIFICATION OF DESIGN SCENARIOS}

Our case study was the coastal area in NE Italy, between Cesena and Venice (EmiliaRomagna and Veneto Italian regions), that is particularly affected in summer by heavy traffic congestion, with consequences for tourism and the environment. This because a unique local road, named the "Romea" (Fig. 2), allows for trips among these touristic places. Furthermore, the "Romea" is considered one of the worst Italian roads with respect to accident risks. Also within the area are several protected environmental areas (e.g. parks and reserves), plus landslide and hydrogeological risk areas, which are crossed by the actual road. 


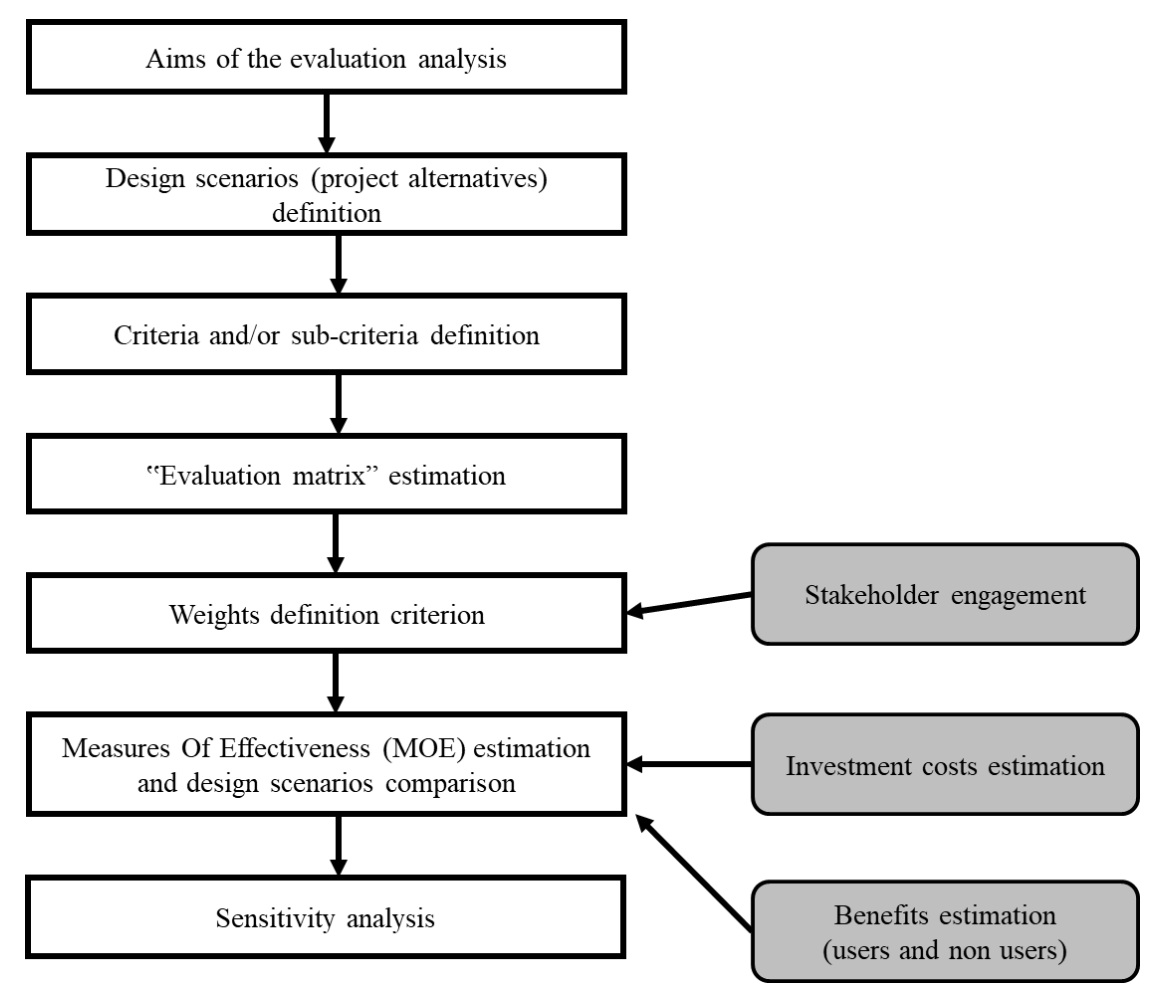

Figure 1: The methodological scheme for multicriteria analysis (MCA).

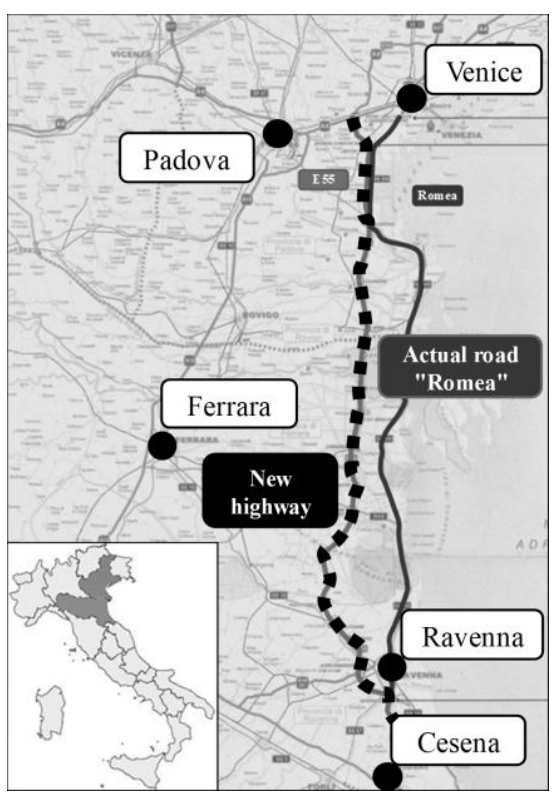

Figure 2: Case study and design scenarios. 
Three different project alternatives (scenarios) were compared:

1. Let it "stand alone", by improving the quality and safety of the actual road path of "Romea";

2. Develop a new toll road (highway);

3. Do as in 2, plus downgrade "Romea" into a "green-way" with restrictive policies for cars and freight vehicles, and improve the quality of life and tourism in the area.

\section{THE ESTIMATION RESULTS}

\subsection{Potential basin and traffic demand estimation}

In the evaluation analysis (e.g. cost-benefit, multi-criteria), the potential basin and traffic demand estimation covered a central role within the benefit estimation produced by a design scenario. In the case study proposed, an ad hoc demand estimation was implemented. Starting from the available traffic counts and origin-destination OD matrix, we estimated a path choice model starting from the results obtained in [11]-[17] for the Italian context. Estimation results showed that the potential demand basin is about 20-25 thousand vehicles/day (cars and freight vehicles); and that the traffic demand catchable by the new highway is about 19 thousand vehicles/day (cars and freight vehicles). A macro-economic trend model was also estimated, to quantify the trend of the demand (vehicles $\times \mathrm{km}$ ) over time (reference period). The model links the trend of the main socio-economic and macro-economic variables GDP, population, fuel/gasoline price and toll) to the trend of the traffic demand.

\subsection{Aims of the evaluation analysis}

In the evaluation analyses, different aims were identified: to improve road efficiency; revenues for the private operator (service provider); user benefits; economic growth; quality of life; and local and global environmental benefits.

\subsection{Definition of criteria and sub-criteria}

For each aim, we defined the evaluation criteria and sub-criteria. With respect to the road efficiency, the criteria were individualized as investment costs, management, and maintenance costs. As benefits for the service provider, two criteria were considered: i) revenues from traffic (as a quantitative indicator); ii) business diversification (as a qualitative indicator) produced by the opening of the new highways (also for the first time, for the private operator). For the transportation users, the generalized transport costs saved (due to shorter path length, less road congestion and the increase in transportation quality) were the criteria considered in the analysis, as suggested in [18] and [19]. As benefits regarding economic growth, both quantitative and qualitative criteria were introduced:

(i) Increase in transport accessibility (quantitative indicator) of the historic centres in the inland, according to indicators proposed by [20], [21];

(ii) Increase in tourism produced by the new green-way road (qualitative indicator: high, middle, low increase); and

(iii) Increase in transport accessibility for freight centres and firms in term of the number of centres/firms within $15 \mathrm{~km}$ from new motorway (quantitative indicators). 
With respect to the quality life, we considered two criteria: First, accident risk reduction (quantitative indicators in term of average number of accidents per year saved in monetary value, according to the EU guidelines); secondly, the increase in social and territorial cohesion (qualitative indicators in terms of being a high, middle, or low increase).

For the local environmental benefits, the criteria considered were the reduction of all the negative emissions (externality) produced both by the cars and by the freight vehicles within the study area. Through the EU guidelines [22], we estimated the overall reduction of acoustic pollution, air pollution and climate-change gases in monetary value (Euro). Furthermore, the percentage of variation of the vehicles $\times \mathrm{km}$ within the protected environmental areas and the risk areas were considered as local environmental benefits. For global environmental impacts, two criteria were considered: First, global warming variation (in equivalent tons of $\mathrm{CO}_{2}$ saved within the time period considered); and second, Disability-Adjusted Life Years (DALY) and usage of primary resources consumption variation (in monetary value, according to the EU guidelines), that measure the number of years lost due to ill-health, disability or early death.

\subsection{Evaluation matrix estimation}

The "evaluation matrix" (sometimes named impact matrix) is the matrix with columns for the design alternatives, to compare the options; and rows equal to all the individual criteria/sub-criteria. The generic element $I_{i j}$ is the value (quantitative or qualitative) of the indicator $I$ relative to the criteria $i$ for the design scenario $j$. In Tables 1 and 2, results deriving from the qualitative and quantitative estimation are reported. The design solution 1, "stand alone", while having lower investment costs, is the one that produces lower benefits both for users and non-users. On the other hand, solution 3 ("new highway and green-way"), even if with the highest investment costs, will produce the highest benefits for system users and nonusers (externality), as reported in Tables 1 and 2.

\subsection{Weights definition criterion through a stakeholder engagement process}

One main activity of a multi-criteria analysis is the weights definition criterion, that is: the estimation of a "weight" for each criterion, aiming to define a relative importance (by weight) for each criterion with respect to the others. The definition of weights is a subjective activity in which the decision-maker, or more frequently the decision-makers and the stakeholders, are called to express subjective judgments of quantitative values.

In our case study, a main originality is that the weights definition process was carried out through the Delphi method, and with stakeholder engagement. The aim of this method was to reach a shared point of view through the interactions between expert stakeholders. For the proposed case study, the two main stakeholders involved are: an expert public decisionmaker (with interests in both user and non-user benefits) and the private operator, the manager of the new highway (private interests of increase profits).

The definition of the weights (priority) to each criterion or sub-criterion was made using a single priority scale [23], [24] that varied from 1 to 9 , according to the following scale: $1-$ Same weight, 3 - Weakly greater weight compared to another one, 5 - Greater weight compared to another one, 7 -Demonstrated relevance compared to another one, 9 - Absolute dominance compared to another one, 2, 4, 6, 8 - Intermediate values between two judgements.

Through "pairs' comparison criteria", a score of importance was assigned to the priorities and through a consistency analysis, we verified the coherence of the subjective judgments of 
the decision-makers (through an Analytic Hierarchy Process). Furthermore, the following rules were considered within the evaluation matrix estimation:

1. Each criterion compared with itself has equal importance; therefore, presents a value equal to 1. For this reason, the elements of the main diagonal are equal to 1 ;

2. All the elements of the matrix have positive values;

3. If the criterion of the column has greater weight than the criterion of the row, the mutual value is inserted.

\subsection{Measures of effectiveness estimation and design scenarios comparison}

For measures of effectiveness (MOE) estimation, matrix normalization was performed. Normalization (or standardization) is an analytical activity that, through mathematical

Table 1: Qualitative impacts assessment (scale from very low (---) to very high (+++)).

\begin{tabular}{|c|c|c|c|c|}
\hline Objectives & Criteria & Stand alone & $\begin{array}{c}\text { New } \\
\text { highway }\end{array}$ & $\begin{array}{c}\text { New highway+ } \\
\text { green-way }\end{array}$ \\
\hline \multirow[b]{2}{*}{ ROAD EFFICIENCY } & Investment costs & - & - & $\cdots$ \\
\hline & $\begin{array}{l}\text { Management and } \\
\text { maintenance costs }\end{array}$ & & -- & -- \\
\hline \multirow{2}{*}{$\begin{array}{l}\text { SERVICE PROVIDER } \\
\text { BENEFITS } \\
\end{array}$} & Income from traffic & & ++ & +++ \\
\hline & Business diversification & & ++ & +++ \\
\hline \multirow[b]{2}{*}{ USERS BENEFITS } & $\begin{array}{l}\text { Cars generalized transport } \\
\text { costs }\end{array}$ & + & +++ & ++ \\
\hline & $\begin{array}{l}\text { Freight vehicles } \\
\text { generalized transport } \\
\text { costs }\end{array}$ & + & +++ & + \\
\hline \multirow{3}{*}{ ECONOMIC GROWTH } & $\begin{array}{l}\text { Tourism promotion: } \\
\text { accessibility to inland } \\
\text { historical centres } \\
\end{array}$ & & +++ & +++ \\
\hline & $\begin{array}{l}\text { Tourism promotion: a } \\
\text { new green-way road } \\
\end{array}$ & + & ++ & +++ \\
\hline & $\begin{array}{l}\text { Freight centres and firms } \\
\text { accessibility }\end{array}$ & & +++ & ++ \\
\hline \multirow{2}{*}{ LIFE QUALITY } & Accidents risk & + & ++ & +++ \\
\hline & Social cohesion & + & ++ & +++ \\
\hline \multirow{4}{*}{$\begin{array}{l}\text { LOCAL } \\
\text { ENVIRONMENTAL } \\
\text { BENEFITS }\end{array}$} & Pollution decrease & + & ++ & +++ \\
\hline & $\begin{array}{l}\text { Protected environmental } \\
\text { areas }\end{array}$ & & + & +++ \\
\hline & Hydrological risk areas & & ++ & ++ \\
\hline & Landslide risk areas & & + & + \\
\hline \multirow{2}{*}{$\begin{array}{l}\text { GLOBAL } \\
\text { ENVIRONMENTAL } \\
\text { BENEFITS }\end{array}$} & Global warming & + & ++ & ++ \\
\hline & $\begin{array}{l}\text { Disability-Adjusted Life } \\
\text { Years and usage of } \\
\text { primary resources }\end{array}$ & + & ++ & ++ \\
\hline
\end{tabular}


Table 2: Quantitative impacts assessment.

\begin{tabular}{|c|c|c|c|c|}
\hline Objectives & Criteria & Stand alone & $\begin{array}{c}\text { New } \\
\text { highway }\end{array}$ & $\begin{array}{c}\text { New highway+ } \\
\text { green-way }\end{array}$ \\
\hline \multirow{2}{*}{ ROAD EFFICIENCY } & $\begin{array}{l}\text { Investment costs (millions of } \\
€)\end{array}$ & -33 & $-2,824$ & $-2,924$ \\
\hline & $\begin{array}{l}\text { Management and maintenance } \\
\text { costs (millions of } € \text { ) }\end{array}$ & & -680 & -680 \\
\hline \multirow{2}{*}{$\begin{array}{l}\text { SERVICE PROVIDER } \\
\text { BENEFITS }\end{array}$} & $\begin{array}{l}\text { Revenues (millions of total } \\
\text { vehicles) }\end{array}$ & & 243 & 285 \\
\hline & $\begin{array}{l}\text { Business diversification (high } \\
=1, \text { medium }=0.66, \text { low }= \\
0.33 \text { ) }\end{array}$ & & 0.66 & 1 \\
\hline \multirow{2}{*}{ USERS BENEFITS } & $\begin{array}{l}\text { Cars generalized transport } \\
\text { costs } \\
\text { (millions of hours saved) }\end{array}$ & 8.5 & 250 & 275 \\
\hline & $\begin{array}{l}\text { Freight vehicles generalized } \\
\text { transport costs (millions of } \\
\text { hours saved) }\end{array}$ & 10.9 & 79 & 112 \\
\hline \multirow{3}{*}{ ECONOMIC GROWTH } & $\begin{array}{l}\text { Tourism promotion: } \\
\text { accessibility to inland } \\
\text { historical centres (number) }\end{array}$ & & 5 & 5 \\
\hline & $\begin{array}{l}\text { Tourism promotion: a new } \\
\text { green-way road (high, } \\
\text { medium, low) }\end{array}$ & 0.33 & 0.66 & 1 \\
\hline & $\begin{array}{l}\text { Freight centres and firms } \\
\text { accessibility (number) }\end{array}$ & & 8 & 8 \\
\hline \multirow[b]{2}{*}{ LIFE QUALITY } & Accidents risk (millions of $€$ ) & 81 & 1,366 & 1,608 \\
\hline & $\begin{array}{l}\text { Social cohesion (high, } \\
\text { medium, low) }\end{array}$ & 0.33 & 0.66 & 1 \\
\hline \multirow{4}{*}{$\begin{array}{l}\text { LOCAL } \\
\text { ENVIRONMENTAL } \\
\text { BENEFITS }\end{array}$} & Pollution (millions of $€$ ) & 1 & 67 & 72 \\
\hline & $\begin{array}{l}\text { Protected environmental areas } \\
\text { (number) }\end{array}$ & & 2,284 & 2,867 \\
\hline & $\begin{array}{l}\text { Hydrological risk areas } \\
\text { (number) }\end{array}$ & & 1,218 & 1,529 \\
\hline & Landslide risk areas (number) & & 1,066 & 1,338 \\
\hline \multirow{2}{*}{$\begin{array}{l}\text { GLOBAL } \\
\text { ENVIRONMENTAL } \\
\text { BENEFITS }\end{array}$} & $\begin{array}{l}\text { Global warming (tons of } \\
\mathrm{C} 02 * 1000 \text { ) }\end{array}$ & 148 & 3,016 & 3,459 \\
\hline & $\begin{array}{l}\text { Disability-Adjusted Life Years } \\
\text { and usage of primary resources } \\
\text { (millions of } € \text { ) }\end{array}$ & 61 & 1,297 & 1,480 \\
\hline
\end{tabular}

formulas, makes the values contained within the evaluation matrix homogeneous and operable. In this way, both different measurement units (e.g. monetary costs and travel time saved) and different absolute values could be compared among the different criteria. In general, this activity commutes the values of the indicators, relative to each criterion, in values within a range scale $(0 ; 1)$. Several techniques are available within the literature to develop this standardization [25], [26].

Once the "weights vector" was defined (defined through stakeholder engagement), the next activity was to multiply each normalized indicator for the corresponding weight of the criterion. Finally, the multi-criteria analysis ends with the sum, for each design solution, of 
the product of its indicators multiplied by the weights. These weighted summations allow the comparison of design scenarios, to choose the best solution to implement. As reported in Table 3, Solution 3 (new highway and green-way) is $23 \%$ better than the second-best solution.

Furthermore, the estimated non-user benefits' incidence was about $80 \%$ of the total, underlining the appropriateness of using this evaluation method to better quantify "nonmonetary" externalities (against, for example, the cost-benefit analysis).

\subsection{Sensitivity analysis}

Finally, we also performed a sensitivity analysis to verify the robustness of the results. The sensitivity analysis consisted in:

Table 3: Normalization of the evaluation matrix, weighted sum and comparison of the design alternatives.

\begin{tabular}{|c|c|c|c|c|}
\hline & & \multicolumn{3}{|c|}{ ALTERNATIVES } \\
\hline Objectives & Criteria & Stand alone & New highway & $\begin{array}{l}\text { New highway+ } \\
\text { green-way }\end{array}$ \\
\hline \multirow[b]{2}{*}{ ROAD EFFICIENCY } & Investment costs & 0.085 & 0.003 & 0.000 \\
\hline & $\begin{array}{l}\text { Management and } \\
\text { maintenance costs }\end{array}$ & 0.048 & 0.000 & 0.000 \\
\hline \multirow{2}{*}{$\begin{array}{l}\text { SERVICE PROVIDER } \\
\text { BENEFITS } \\
\end{array}$} & Income from traffic & 0.000 & 0.055 & 0.065 \\
\hline & Business diversification & 0.000 & 0.013 & 0.027 \\
\hline \multirow[b]{2}{*}{ USERS BENEFITS } & $\begin{array}{l}\text { Cars generalized } \\
\text { transport costs }\end{array}$ & 0.000 & 0.065 & 0.072 \\
\hline & $\begin{array}{l}\text { Freight vehicles } \\
\text { generalized transport } \\
\text { costs }\end{array}$ & 0.000 & 0.060 & 0.089 \\
\hline \multirow{3}{*}{ ECONOMIC GROWTH } & $\begin{array}{l}\text { Tourism promotion: } \\
\text { accessibility to inland } \\
\text { historical centres }\end{array}$ & 0.000 & 0.044 & 0.044 \\
\hline & $\begin{array}{l}\text { Tourism promotion: a } \\
\text { new green-way road }\end{array}$ & 0.000 & 0.024 & 0.048 \\
\hline & $\begin{array}{l}\text { Freight centres and firms } \\
\text { accessibility }\end{array}$ & 0.000 & 0.065 & 0.065 \\
\hline \multirow{2}{*}{ LIFE QUALITY } & Accidents risk & 0.000 & 0.086 & 0.102 \\
\hline & Social cohesion & 0.000 & 0.016 & 0.032 \\
\hline \multirow{4}{*}{$\begin{array}{l}\text { LOCAL ENVIRONMENTAL } \\
\text { BENEFITS }\end{array}$} & Pollution decrease & 0.000 & 0.080 & 0.085 \\
\hline & $\begin{array}{l}\text { Protected environmental } \\
\text { areas }\end{array}$ & 0.000 & 0.036 & 0.045 \\
\hline & Hydrological risk areas & 0.000 & 0.045 & 0.056 \\
\hline & Landslide risk areas & 0.000 & 0.045 & 0.056 \\
\hline \multirow{4}{*}{$\begin{array}{l}\text { GLOBAL } \\
\text { ENVIRONMENTAL } \\
\text { BENEFITS }\end{array}$} & Global warming & 0.000 & 0.024 & 0.028 \\
\hline & $\begin{array}{l}\text { Disability-Adjusted Life } \\
\text { Years and usage of } \\
\text { primary resources }\end{array}$ & 0.000 & 0.024 & 0.028 \\
\hline & & 0.133 & 0.683 & 0.840 \\
\hline & & & diff\% & $23 \%$ \\
\hline
\end{tabular}


(i) Applying different standardization functions to the evaluation matrix;

(ii) Varying the number of criteria within the individualized aims (to avoid that aims with a greater number of criteria "weight" more in the analysis);

(iii) Varying the investment costs (assuming they were underestimated) and road traffic demand estimated (assuming it was overestimated) on the new road (potential demand basin).

By way of example, given in the graph below (Fig. 3), the results of the simulations show a "robust" design scenario; thus, confirming that design alternative 3 is the best solution to be implemented from the economic-social point of view.

\section{CONCLUSIONS AND FUTURE DEVELOPMENTS}

The low accessibility of transportation to the main Italian touristic places during the summer period often produces high levels of road congestion and negative environmental impacts. This is the case in the coastal area between Cesena and Venice, which is particularly affected by this tourist access phenomenon. Beginning from these considerations, our aim was the evaluation of a new highway to improve transportation accessibility for the area. The MCA was identified as the rational evaluation process to use to verify the sustainability (economic, social and environmental) of this transportation-related project. One of the main findings of the research was the applied evaluation methodology. A rational and participated weights definition criterion process was implemented, through a "Delphi method" within a Public Engagement process. The MCA results showed that the best design alternative was the construction of a highway plus the realization of a "green-way". Furthermore, the estimated non-user's benefits incidence was about $80 \%$ of the total, underlining the appropriateness in using this evaluation method as a useful way to better quantify the non-monetary externalities

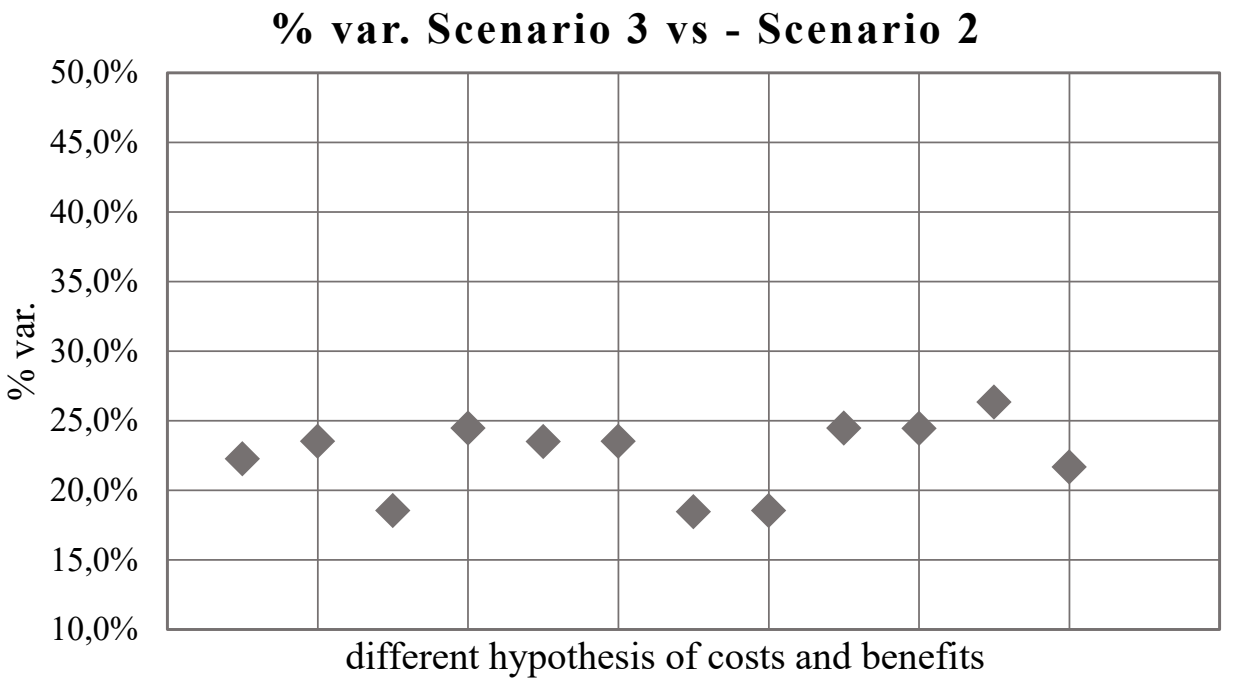

Figure 3: Example of sensitivity analysis results: percentage variation of Scenario 3 (best scenario) with respect to Scenario 2 (second-best solution) in different hypotheses using costs and benefits (users and non-users). 
(against the cost-benefit analysis). Finally, to verify the robustness of the results, we also performed a sensitivity analysis, confirming the main results. Among the results from the research perspective is the development of a benefit-cost analysis, to be able to compare the results obtained.

\section{REFERENCES}

[1] Ricardo-AEA DG MOVE, Update of the Handbook on External Costs of Transport. Final Report, Report for the European Commission, 2014.

[2] Cascetta, E., Cartenì, A., Pagliara, F. \& Montanino, M., A new look at planning and designing transportation systems: a decision-making model based on cognitive rationality, stakeholder engagement and quantitative methods. Transport Policy, 38, pp. 27-39, 2015.

[3] Cartenì, A., Urban sustainable mobility. Part 1: Rationality in transport planning. Transport Problems, 9(4), pp. 39-48, 2014.

[4] Cartenì, A., A cost-benefit analysis based on the carbon footprint derived from plugin hybrid electric buses for urban public transport services. WSEAS Transactions on Environment and Development, 14, pp. 125-135, 2018.

[5] Cartenì, A. \& Henke, I., External costs estimation in a cost-benefit analysis: The new Formia-Gaeta tourist railway line in Italy. Conference Proceedings - 2017 17th IEEE International Conference on Environment and Electrical Engineering and 2017 1st IEEE Industrial and Commercial Power Systems Europe, EEEIC / I and CPS Europe 2017, art. no. 7977614, 2017.

[6] Botte, M., Di Salvo, C., Caropreso, C., Montella, B. \& D’Acierno, L., Defining economic and environmental feasibility thresholds in the case of rail signalling systems based on satellite technology. Proceedings of the 16th IEEE International Conference on Environment and Electrical Engineering (IEEE EEEIC 2016), Florence, Italy, June 2016, art. no. 7555878, pp. 251-255, 2016. ISBN: 978-1-5090-2320-2.

[7] Caropreso, C., Di Salvo, C., Botte, M. \& D'Acierno, L., A long-term analysis of passenger flows on a regional rail line. Int J Transport Development Integration, 1(3), pp. 329-338, 2017. ISSN: 2858-8305.

[8] Roy, B. \& Vincke, P., Multicriteria analysis: survey and new directions. Europ $J$ Operational Res, 8(3), pp. 207-218, 1981. ISSN: 0377-2217.

[9] Wang, J.J., Jing, Y.Y., Zhang, C.F. \& Zhao, J.H., Review on multi-criteria decision analysis aid in sustainable energy decision-making. Renewable Sustainable Energy Rev, 13(9), pp. 2263-2278, 2009. ISSN: 1364-0321.

[10] Malczewski, J., GIS-based multicriteria decision analysis: a survey of the literature. Int J Geograph Inform Sci, 20, pp. 703-726, 2006.

[11] Cantarella, G.E., de Luca, S. \& Cartenì, A., Stochastic equilibrium assignment with variable demand: theoretical and implementation issues. Europ J Operational Res, 241(2), pp. 330-347, 2015.

[12] Cartenì, A., Urban sustainable mobility. Part 2: Simulation models and impacts estimation. Transport Problems, 10(1), pp. 5-16, 2015. ISSN: 1896-0596.

[13] Cartenì, A., Updating demand vectors using traffic counts on congested networks: A real case application. WIT Transactions on the Built Environment, 96, pp. 211-221, 2007.

[14] Cartenì, A. \& Russo, F., A distribution regional freight demand model. Adv Transport, 16, pp. 275-285, 2004. ISSN: 1462608X.

[15] Bifulco, G.N., Cartenì, A. \& Papola, A., An activity-based approach for complex travel behaviour modeling. Europ Transport Res Rev, 2(4), pp. 209-221, 2010. 
[16] Cartenì, A. \& Punzo, V., Travel time cost functions for urban roads: A case study in Italy. WIT Transactions on the Built Environment, 96, pp. 233-243, 2007.

[17] de Luca, S. \& Cartenì, A., A multi-scale modelling architecture for estimating of transport mode choice induced by a new railway connection: The Salerno-University of Salerno-Mercato San Severino Route [Un'architettura modellistica multi-scala per la stima delle ripartizioni modali indotte da un nuovo collegamento ferroviario: il caso studio della tratta Salerno-Università di Salerno-Mercato San Severino]. Ingegneria Ferroviaria, 68(5), pp. 447-473, 2013.

[18] Cascetta, E. \& Cartenì, A., A quality-based approach to public transportation planning: theory and a case study. Int J Sustainable Transport, 8(1), pp. 84-106, 2014.

[19] Cascetta, E., Cartenì, A. \& Carbone, A., The quality in public transportation. The Campania regional metro system [La progettazione quality-based nel trasporto pubblico locale. Il sistema di metropolitana regionale delia Campania]. Ingegneria Ferroviaria, 68(3), pp. 241-261, 2013. ISSN: 0020-0956.

[20] Cascetta, E., Cartenì, A. \& Montanino, M., A behavioral model of accessibility based on the number of available opportunities. J Transport Geography, 51, pp. 45-58, 2016.

[21] Cartenì, A., Accessibility indicators for freight transport terminals. Arabian J Sci Engin, 39(11), pp. 7647-7660, 2014.

[22] European Commission, Guide to Cost-Benefit Analysis of Investment Projects, 2015.

[23] Saaty, T.L., The Analytic Hierarchy Process, McGraw-Hill: New York, 1980.

[24] Figueira, J., Greco, S. \& Ehrgott, M., (eds), Multiple criteria decision analysis: state of the art surveys. International Series in Operations Research and Management Science, 78, Springer-Verlag: Boston, 2005.

[25] Swarnkar, R., Chaube, A., Harding, J., Das, B. \& Tiwari, M.K., Prioritising tendering activities for small to medium-sized enterprises (SMEs). Technology Management Conference (ICE) 2009 IEEE International, pp. 1-7, 2009.

[26] Kuo, M.S., Liang, G.S. \& Huang, W.C., Extensions of the multicriteria analysis with pairwise comparison under a fuzzy environment. Int $J$ Approx Reason, 43, pp. 268285, 2006. 